\title{
Giant-cell tumor of bone: treatment options and role of denosumab
}

This article was published in the following Dove Press journal:

Biologics:Targets and Therapy

14 July 2015

Number of times this article has been viewed

\author{
Arun S Singh' \\ Neal S Chawla ${ }^{2}$ \\ Sant P Chawla ${ }^{2}$ \\ 'Sarcoma Service, Division of \\ Hematology/Oncology, University \\ of California, Los Angeles, ${ }^{2}$ Sarcoma \\ Oncology Center, Santa Monica, CA, \\ USA
}

\begin{abstract}
Giant-cell tumor of bone is a rare, locally aggressive tumor that typically occurs in the bones of skeletally mature young adults in their second to fourth decades. Traditionally, surgery has been the mainstay of therapy for this disease, but the disease can recur even with optimal procedures. Furthermore, it may occur in locations where a surgical approach would be morbid. The maturation of the understanding of the role of the receptor activator of nuclear factor- $\kappa B$ ligand (RANKL) in the pathophysiology of giant-cell tumor of bone has led to the use of denosumab, a monoclonal antibody against RANKL, in this disease. In 2013, the US Food and Drug Administration approved denosumab for use in patients with recurrent/unresectable/ metastatic giant-cell tumor of bone or for patients in whom surgery would be morbid.
\end{abstract}

Keywords: denosumab, giant-cell tumor of bone, sarcoma, targeted therapy, RANKL

\section{Introduction}

Giant-cell tumor of bone (GCTB) is a rare tumor typically affecting the bones of skeletally mature young adults, with peak incidence in the third and fourth decades of life. It can occur in any bone and can incur significant morbidity, due to a tendency to occur in the bones surrounding the wrist and knee, as well as the axial skeleton. The disease rarely metastasizes, but there appears to be an increased incidence of pulmonary metastases in patients with recurrent disease. GCTBs are characterized by distinctive multinucleated giant cells that need to be distinguished from other distinct sarcomas, including malignant giant-cell sarcoma and giant-cell-rich osteosarcoma. These tumors are heterogeneous in composition, and thus sampling errors from biopsies can lead to diagnostic errors. ${ }^{1,2}$

The discovery of the important role of the receptor activator of nuclear factor- $\mathrm{\kappa B}$ (RANK)/RANK-ligand (RANKL) pathway in the pathogenesis of this disease has led to the development of the monoclonal antibody denosumab against RANKL. Denosumab is the only US Food and Drug Administration (FDA)-approved drug for the treatment of GCTB. ${ }^{3}$ Herein, we discuss the role of denosumab in modifying the pathogenesis of GCTB and the evolving management of GCTB with the introduction of denosumab.

\section{Clinical characteristics of giant-cell tumor of bone}

GCTB classically presents as a swollen, painful, bony lesion characterized by lytic areas on plain radiographs. These are locally aggressive neoplasms with a low likelihood of dissemination. They are most commonly centered on the epiphyses of the long bones, and nearly $50 \%$ of cases affect the distal femur or proximal tibia.
Correspondence: Arun S Singh

Sarcoma Service, Division of Hematology/

Oncology, University of California, Los

Angeles, 2825 Santa Monica Boulevard -

Suite 200, Santa Monica, CA 90404, USA

$\mathrm{Tel}+|310829547|$

$\mathrm{Fax}+\mathrm{I} 3108296192$

Email asingh@mednet.ucla.edu 
They can also involve the metaphysis and also extend to the subchondral plate. In severe cases, there is joint involvement, which portends more extensive surgical procedures. These tumors are generally solitary, but can be multifocal in rare instances $(<1 \%)$. They are classified using the Campanacci system, with grade 1 indicating tumors that have an intact cortex and are well marginated, grade 2 indicating more extensive intraosseous lesions that have cortical erosion but not loss of cortical borders, and grade 3 lesions that have broken through the cortex and extend into the surrounding soft tissue. ${ }^{4}$

The diagnosis can be suspected by the presence of a lytic lesion on plain radiographs or computed tomography scans, but several other differentials exist for lytic lesions, including multiple myeloma, metastatic carcinoma, aneurysmal bone cysts, fibrous dysplasia, telangiectatic osteosarcoma, Langerhans cell histiocytosis, and other rare entities. Any evidence of new bone formation should bring up the possibility of osteosarcoma, which can be giant-cell-rich osteosarcoma. On positron-emission tomography (PET) imaging, these lesions will typically be 2-deoxy-2- $\left({ }^{18} \mathrm{~F}\right)$ fluorodeoxyglucose (FDG)-avid; this finding is thought to be due to the highly metabolic giant cell tumour(GCT) infiltrate. ${ }^{5}$ While the incidence is low, patients should have their lungs periodically imaged, as dissemination to the lung is seen, albeit rarely and more frequently in the setting of recurrent disease. Metastatic lung disease is seen in less than $5 \%$ of patients with recurrent GCTB. These pulmonary lesions are generally slow-growing. Some references in the literature refer to these as "benign pulmonary deposits". However, care must be taken, as these can also represent metastatic giant-cell-rich sarcomas or giant-cell sarcomas, which behave more aggressively. Of note, case reports of metastases to the skin, lymph nodes, breast, and heart have been documented. ${ }^{6}$

\section{Pathophysiology of giant-cell tumor of bone}

A deeper understanding of the molecular biology governing the development of GCTB has led to the development of denosumab for this disease. ${ }^{3}$ When GCTB is biopsied, the major findings include areas of bone erosion lined by multinucleated giant cells, a macrophage-derived mononuclear population, and a mesenchymally derived stromal layer thought to be the malignant element of a GCTB. ${ }^{6}$ Evidence that the stromal cells are the neoplastic component of GCTB comes from their ability to form tumors in mice and their ability to proliferate and be maintained in cell-culture systems. $^{7-9}$
The stromal layer of a GCT is composed of cells with a variety of nonclonal, karyotypic anomalies, including insertions, deletions, translocations, and chromosomal rearrangements. ${ }^{6,10-12}$ The relevance of these genetic lesions to the manifestation of the disease or for prognostication is not clear at this time, and clear driver mutations in this disease have not been identified. The cells may or may not possess mutations in p53; however, the importance of this fact is not clear at this time. Factors leading to the genetic derangements in this population are not well understood. Moreover, the heterogeneity of the genetic changes leading to a final common phenotype indicates that there is unlikely to be a common genetic cause.

The stromal cells are thought to orchestrate the recruitment of monocyte cells to their milieu and to incite the production of the multinucleated giant cells (osteoclastomas). Stromal cells produce SDF-1 and MCP-1, which recruits CD68-positive monocytes that also express a variety of macrophage markers. Evidence indicates that the stromal compartment also produces VEGF, which can function to attract CD68 cells that also express VEGFR1 (Flt1). As an aside, the production of VEGF by GCT stromal cells is the likely reason some of these tumors are hypervascular, and intratumoral bleeding can also be noted. ${ }^{1}$

The discovery of the important role of RANKL in GCTB has been the key to understanding the pathophysiology of this disease. RANKL was originally identified from a murine thymoma line in studies done to elucidate TNFR homologues and subsequently shown to be important in the development of osteoclasts. ${ }^{3,13}$ RANKL secreted by the immature osteoblast-like stromal cells of these tumors not only aids in the recruitment of monocyte precursors but also in the formation of osteoclast-like giant cells. Following recruitment, the monocyte precursors are induced to express RANK via Macrophage-colony-stimulating factor (M-CSF) secreted by the stromal compartment. The recruited monocytes also undergo proliferation and differentiation in response to M-CSF (Figure 1). This is borne out in tumor specimens where RANKL expression has been observed to be increased in GCTB compared to control tissues. The essential question as to why RANKL is increased in GCTB is unclear in the literature. One hypothesis points to a role for PTHrP in increasing local calcium levels, which can lead to increased RANKL expression. ${ }^{14}$ However, a definitive answer to this question is currently lacking.

Presumably, RANKL leads to cellular fusion of the recruited monocytes, forming the multinucleated giant cells characteristic of this disease. It may be that these giant cells manifest via cellular contact with the diseased 


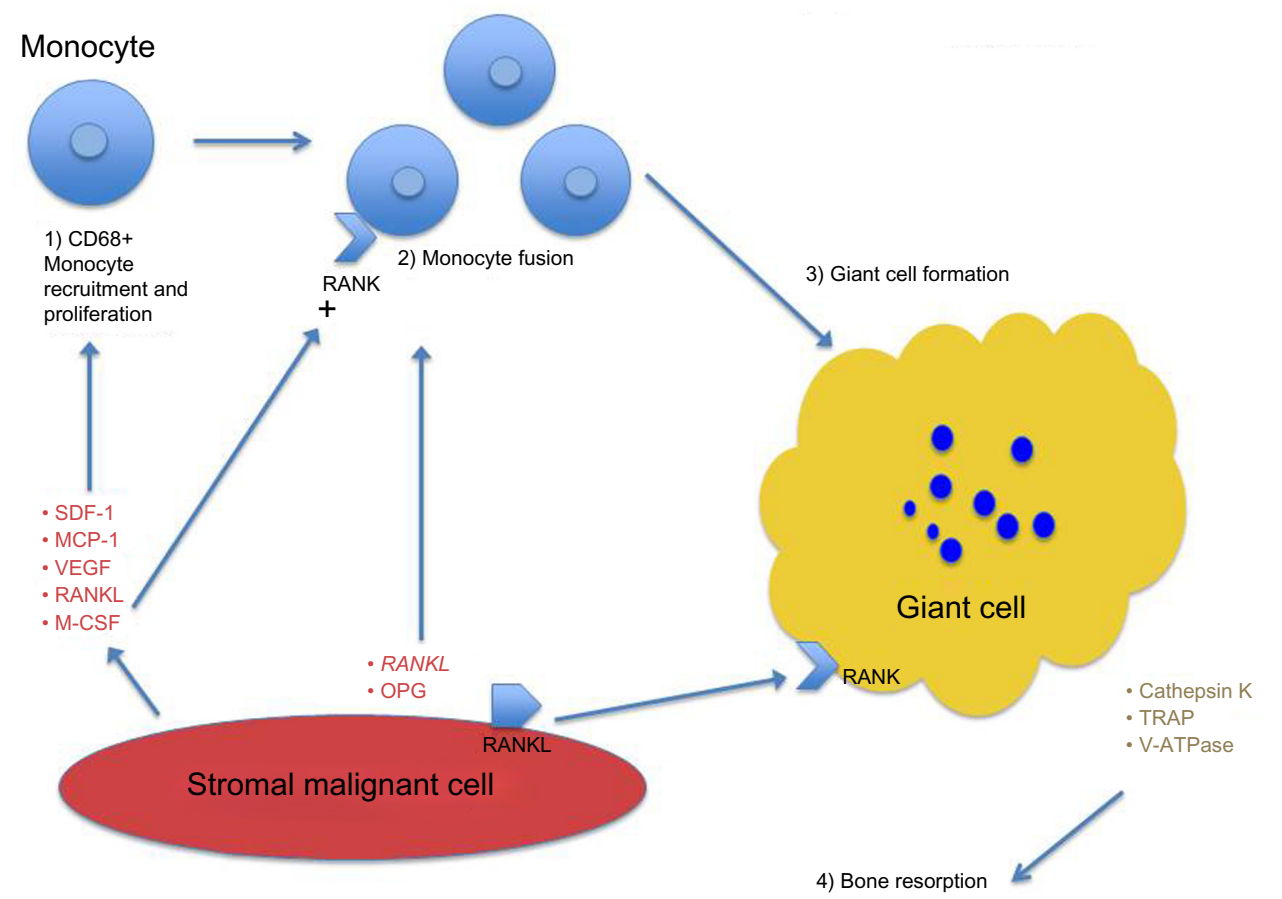

Figure I Pathophysiology of giant-cell tumor of bone.

Abbreviation: RANKL, receptor activator of nuclear factor-kB ligand; SDF-I, Stromal cell-derived factor I; MCP-I, Monocyte Chemoattractant Protein-I; OPG, osteoprotegrin; TRAP, tartrate resistant acid phosphatase; RANK, receptor activator of NF-kappaB.

stromal compartment, but there is also evidence pointing to the existence of soluble RANKL, which may orchestrate the formation of multinucleate giant cells via a paracrine mechanism. In the serum of patients with GCTB, elevated RANKL levels have been observed. The resultant giant cells physiologically behave like osteoclasts. They express cathepsin $\mathrm{K}$ and vacuolar $\mathrm{H}^{+}$ATPase, which degrade the organic and hydroxyapatite components of bone, resulting in an osteolytic lesion of the bone. Moreover, several matrix metalloproteinases have been found to be elevated in GCTB, and their role in degrading bone has been extrapolated from their well-established role in stromal reorganization. ${ }^{6}$

\section{Management of giant-cell tumor of bone}

Surgery has been the mainstay of therapy for GCTB, as the tumor is rarely metastatic and high cure rates have been observed for localized disease. However, the surgical approach has to be carefully measured in all patients depending on the disease extent, both in the bone and association with the joints and surrounding neurovasculature. Adequate resection of bone lesions may not be feasible in such sites as the sacrum, spine, and base of the skull. Preoperative plain films and computed tomography scans can define the extent of the bone lesion and presence of a pathologic fracture. Joint and soft-tissue and neurovascular involvement of these tumors is best evaluated by magnetic resonance imaging.
Bone scans can help to define whether there is multifocal disease. PET scans can be useful, as the giant cell compartment of GCTB is FDG-avid, but the role is not well defined at this time. Of note, it has been demonstrated that PET imaging can be used to follow the response to such therapies as denosumab in GCTB. ${ }^{5}$

Lesional excision and en bloc resection are reserved for more advanced cases that would not lead to functional deficits or excessive morbidity. But the most commonly used technique for treating GCTB has involved intralesional curettage followed by bone cement as an adjunct. While there is no prospective evaluation of the use of adjuncts following curettage in GCTB, much less any trial demonstrating the superiority of cement compared to other adjuncts, such as phenol or zinc chloride, bone cement is preferred by many surgeons, as it allows ready evaluation for tumor recurrence. Also, retrospective studies have indicated that it is associated with a lower rate of local failure. ${ }^{15}$

For lesions that cannot by fully excised or are in such locations as the sacrum, where surgery would be morbid, radiation used to be considered a reasonable choice. The long term local control rate has been documented to range from $60 \%$ to $84 \%{ }^{13,16-18}$ However, radiation has fallen out of favor, due to the possibility of the development of radiation-associated sarcomas. ${ }^{19}$ This possibility should be carefully considered before employing this modality. Chemotherapy and IFN $\alpha$ have also been used to treat GCTB, but there are no random- 
ized controlled trials to guide their use. Chemoembolization of sacral tumors has been demonstrated to give long-term control of the disease; however, due to the small numbers, it was unclear whether cisplatin added additional benefit. ${ }^{20}$ Due to their ability to inhibit osteoclastic activity, bisphosphonates have also been used in the treatment of GCTB. Case-report studies and one retrospective study have indicated that these drugs may reduce local recurrences after surgery. ${ }^{21,22}$ There is also limited experience with other systemic therapies (Table 1).

\section{Development of denosumab}

Normal bone homeostasis depends on the tightly regulated dynamic interplay between osteoclasts and osteoblasts. It was observed that mice in which RANK or RANKL was knocked out developed osteopetrosis due to defective osteoclastogenesis and hence defective bone remodeling. In addition, mice deficient in osteoprotegerin, a soluble decoy receptor for RANKL, developed osteopenia due to unopposed osteoclastic activity. ${ }^{18}$ This understanding led to developmental efforts for finding antibodies against RANKL, which culminated in denosumab, a fully human $\operatorname{IgG}_{2}$ monoclonal antibody that binds soluble and membrane bound RANKL with high affinity. ${ }^{3}$ Today, denosumab has indications for osteoporosis treatment, prevention of skeletal-related morbidity in patients with bony metastases, hypercalcemia of malignancy, prevention of aromatase and androgen deprivation-induced bone loss, and for GCTB.

Evidence of denosumab's ability to clinically modulate bone physiology combined with an understanding that
RANKL was central to the pathogenesis of GCTB led to an open-label Phase II study of denosumab in GCTB. ${ }^{18,23}$ In this study, 37 patients with recurrent/unresectable GCTB were treated with denosumab until surgery, progression, or an adverse event necessitating medication withdrawal. Of the 20 patients assessed by histologic response after treatment, all 20 patients were found to have greater than $90 \%$ elimination of giant cells relative to baseline, and $84 \%$ of patients were reported by investigators to have received clinical benefit. Also, stromal cell density was reduced and embedded with new osteoid formation. Radiographically, ten of 15 had a lack of progression, and decreased FDG avidity was noted on PET scans in responsive patients. Five patients had grade 3-4 adverse events, only one of which was thought to be treatment-related, while two patients experienced disease progression while on the drug. As a corollary to this work, the author (SPC) also looked at the pathologic changes in GCTB samples from patients treated with denosumab. A decrease of $90 \%$ or more of tumor-associated giant cells and a reduction in tumor stromal cells was observed in 20 of 20 patients. Moreover, 13 of 20 patients were noted to have an increase in the formation of newly woven bone in the areas where there were previously RANKL-positive stromal cells. $^{24}$

The success of this signal-finding study led to an international, open-label Phase II trial in two parallel cohorts in patients at least 12 years old who had histologically confirmed GCTB and measurable disease. In the first cohort consisting of patients with surgically unsalvageable GCTB, 163 of 169 patients had no disease progression, with a median

Table I Systemic therapies for giant-cell tumor of bone (GCTB)

\begin{tabular}{|c|c|c|c|}
\hline Therapy & Type of study & Patients, $\mathbf{n}$ & Outcome \\
\hline Sunitinib ${ }^{28}$ & Phase II & I & $68+$ weeks on study SD \\
\hline \multirow[t]{2}{*}{ Bisphosphonates $^{21}$} & Retrospective & 25 & Confounded by use of CT, XRT, IFN $\alpha$, Emb \\
\hline & & & In vitro inhibition of GCTB-derived osteoclast resorption \\
\hline Bisphosphonates $^{29}$ & $\begin{array}{l}\text { Retrospective, case-controlled, after } \\
\text { curettage }\end{array}$ & 44 & $\begin{array}{l}\text { One of } 24 \text { developed recurrence in the bisphosphonate } \\
\text { group; six of } 20 \text { in the control group }\end{array}$ \\
\hline Zoledronic acid ${ }^{30}$ & Phase II, after intralesional curettage & 24 & $82 \%$ RFS at 60 months with zoledronic acid \\
\hline Calcitonin & Retrospective, calcitonin after curettage & 25 & $52 \%$ had local recurrences \\
\hline \multirow[t]{8}{*}{ Denosumab $23,26,31$} & Phase I & 37 & 20 of 20 patients with histologic response \\
\hline & & & Ten of 15 with radiologic response \\
\hline & & & Five of 27 had grade $3-5$ AEs \\
\hline & Phase II & 282 & $\begin{array}{l}\text { I } 63 \text { of } 169 \text { had no disease progression in cohort I (not a } \\
\text { surgical candidate) }\end{array}$ \\
\hline & & & $72 \%$ had objective tumor response \\
\hline & & & Three patients with ONJ \\
\hline & & & $9 \%$ SAEs reported \\
\hline & Phase II & 271 & Most patients had improvement in pain within 2 months \\
\hline
\end{tabular}

Abbreviations: SD, stable disease; CT, computed tomography; XRT, radiation therapy; IFN, interferon; Emb, embolization; RFS, recurrence-free survival; AEs, adverse events; ONJ, osteonecrosis of the jaw; SAEs, serious AEs. 
follow-up of 13 months. In a second cohort of 100 patients whose surgery was associated with significant morbidity, 16 of 26 patients who underwent surgery had less morbid procedures than were planned, and $74 \%$ of these patients did not have surgery. Three of 282 and 15 of 282 patients had osteonecrosis of the jaw and hypocalcemia, respectively. Common grade 3/4 adverse events included hypophosphatemia (3\%), anemia, and back and extremity pains (1\%). In $9 \%$ of patients, a serious adverse event was reported. Based on this study, on June 13, 2013, the FDA granted approval through the orphan-product designation because of the rarity of GCTB for skeletally mature patients with surgically unresectable GCTB or for patients whose resection would be associated with undue morbidity. ${ }^{25}$ Only six patients had progression while on the study. ${ }^{26}$ Doses approved included $120 \mathrm{mg}$ subcutaneous injection weekly for 3 weeks, followed by monthly injections.

\section{Future of denosumab in GCTB}

Currently, denosumab is being evaluated in over 30 different studies for a wide range of indications, most of which involve bone physiology. However, several questions remain about the use of this drug in GCTB. It is clear that the drug is useful in the neoadjuvant setting, but the optimal duration of neoadjuvant treatment remains to be defined. It is the authors' impression that this will have to be individualized to each situation, as the location, degree of tumor involvement, presence of fracture, and expertise of local surgeons will vary significantly, and thus clinical judgment will have to be used to determine what the optimal treatment duration is. Additionally, follow up will be required to ascertain the long-term effects of denosumab therapy, which are currently unknown.

Likewise, in the adjuvant setting, there are no data regarding how long patients who have had neoadjuvant denosumab should remain on this medication. In the registration trial for denosumab in GCTB, patients received six doses of denosumab after surgery. In a disease for which recurrences are possible even with $\mathrm{R} 0$ resections, the recurrence rate in the setting of denosumab use and the duration of adjuvant denosumab use will have to be defined. Moreover, the long-term effects of denosumab therapy on patients with bones with normal density is unknown. While patients with osteoporosis have been treated for many years, this situation is different compared to patients with bony metastases and GCTB, who generally have normal bone densities. While mice treated with antibodies to RANKL have developed osteopetrosis, it remains to be seen what the effects of denosumab use on long-term bone density shall be. One case report of a 10-year-old girl with metastatic GCTB developing an osteopetrotic-like bone state following 20 months of treatment with denosumab has been reported. ${ }^{27}$

In the same vein, resistance to this therapy is not well defined. Thomas et $\mathrm{al}^{23}$ identified a few patients who were refractory to denosumab therapy with up-front treatment. Also, the treating physician must be aware of the possibility of mistaking giant-cell sarcoma or giant-cell-rich osteosarcoma, as these tumors will not respond to denosumab. As such, patients who continue to show rapid growth while on denosumab should be suspected of having giant-cell sarcoma or giant-cell-rich osteosarcoma. At this time, resistance to denosumab in GCTB after initial response has not been reported. Adequate vitamin D and calcium supplementation is of paramount importance during denosumab therapy. Osteonecrosis of the jaw is an important adverse effect of denosumab. Oral and dental examination should be performed before and during denosumab therapy. Major dental procedures, such as tooth extraction, root canal, and dental implantation, should be avoided, as they have been associated with a high risk of osteonecrosis of the jaw development. If a patient develops ulcers around the gums and dental ridge, denosumab must be discontinued, and the patient should be evaluated by dental services.

\section{Conclusion}

The understanding of the contribution of RANKL to the pathogenesis of GCTB has led to the approval of denosumab to treat this disease in patients who are inoperable or where operations would be morbid. The drug has proven to be remarkably effective, with few side effects. The introduction of denosumab has altered the treatment paradigm of many patients, but several questions remain about the optimal use of this medication, which will require carefully constructed studies to address.

\section{Disclosure}

The authors report no conflicts of interest in this work.

\section{References}

1. Fletcher CD, Unni KK, Mertens F. Pathology and Genetics of Tumours of Soft Tissue and Bone. Lyon: International Agency for Research on Cancer; 2002.

2. Thomas DM. RANKL, denosumab, and giant cell tumor of bone. Curr Opin Oncol. 2012;24(4):397-403.

3. Lacey DL, Boyle WJ, Simonet WS, et al. Bench to bedside: elucidation of the OPG-RANK-RANKL pathway and the development of denosumab. Nat Rev Drug Discov. 2012;11(5):401-419.

4. Campanacci M, Baldini N, Boriani S, Sudanese A. Giant-cell tumor of bone. J Bone Joint Surg Am. 1987;69(1):106-114. 
5. Skubitz K, Thomas D, Chawla S, Staddon A. Response to treatment with denosumab in patients with giant cell tumor of bone (GCTB): FDG PET results from two phase 2 trials. J Clin Oncol. 2014; 32(5 Suppl):10505.

6. Cowan RW, Singh G. Giant cell tumor of bone: a basic science perspective. Bone. 2013;52(1):238-246.

7. Byers VS, Levin AS, Johnston JO, Hackett AJ. Quantitative immunofluorescence studies of the tumor antigen-bearing cell in giant cell tumor of bone and osteogenic sarcoma. Cancer Res. 1975;35(9):2520-2531.

8. Goldring SR, Roelke MS, Petrison KK, Bhan AK. Human giant cell tumors of bone identification and characterization of cell types. J Clin Invest. 1987;79(2):483-491.

9. Wülling M, Delling G, Kaiser E. The origin of the neoplastic stromal cell in giant cell tumor of bone. Hum Pathol. 2003;34(10):983-993.

10. Bardi G, Pandis N, Mandahl N, et al. Chromosomal abnormalities in giant cell tumors of bone. Cancer Genet Cytogenet. 1991;57(2):161-167.

11. Bridge JA, Mouron BJ, Neff JR, Bhatia PS. Significance of chromosomal abnormalities in a malignant giant cell tumor of bone. Cancer Genet Cytogenet. 1991;57(1):87-92.

12. Bridge JA, Neff JR, Bhatia PS, Sanger WG, Murphey MD. Cytogenetic findings and biologic behavior of giant cell tumors of bone. Cancer. 1990;65(12):2697-2703.

13. Anderson DM, Maraskovsky E, Billingsley WL, et al. A homologue of the TNF receptor and its ligand enhance T-cell growth and dendritic-cell function. Nature. 1997;390(6656):175-179.

14. Cowan RW, Singh G, Ghert M. PTHrP increases RANKL expression by stromal cells from giant cell tumor of bone. J Orthop Res. 2012;30(6): $877-884$.

15. Kivioja AH, Blomqvist C, Hietaniemi K, et al. Cement is recommended in intralesional surgery of giant cell tumors: a Scandinavian Sarcoma Group study of 294 patients followed for a median time of 5 years. Acta Orthop. 2008;79(1):86-93.

16. Feigenberg SJ, Marcus RB Jr, Zlotecki RA, Scarborough MT, Berrey BH, Enneking WF. Radiation therapy for giant cell tumors of bone. Clin Orthop Relat Res. 2003(411):207-216.

17. Ruka W, Rutkowski P, Morysiński T, et al. The megavoltage radiation therapy in treatment of patients with advanced or difficult giant cell tumors of bone. Int J Radiat Oncol Biol Phys. 2010;78(2):494-498.

18. Bucay N, Sarosi I, Dunstan CR, et al. Osteoprotegerin-deficient mice develop early onset osteoporosis and arterial calcification. Genes Dev. 1998;12(9):1260-1268.
19. Rock MG, Sim FH, Unni KK, et al. Secondary malignant giant-cell tumor of bone. Clinicopathological assessment of nineteen patients. J Bone Joint Surg Am. 1986;68(7):1073-1079.

20. Lin PP, Guzel VB, Moura MF, et al. Long-term follow-up of patients with giant cell tumor of the sacrum treated with selective arterial embolization. Cancer. 2002;95(6):1317-1325.

21. Balke M, Campanacci L, Gebert C, et al. Bisphosphonate treatment of aggressive primary, recurrent and metastatic giant cell tumour of bone. BMC Cancer. 2010;10:462.

22. Cheng YY, Huang L, Lee KM, Xu JK, Zheng MH, Kumta SM. Bisphosphonates induce apoptosis of stromal tumor cells in giant cell tumor of bone. Calcif Tissue Int. 2004;75(1):71-77.

23. Thomas D, Henshaw R, Skubitz K, et al. Denosumab in patients with giant-cell tumour of bone: an open-label, phase 2 study. Lancet Oncol. 2010;11(3):275-280.

24. Branstetter DG, Nelson SD, Manivel JC, et al. Denosumab induces tumor reduction and bone formation in patients with giant-cell tumor of bone. Clin Cancer Res. 2012;18(16):4415-4424.

25. US Food and Drug Administration. FDA approves Xgeva to treat giant cell tumor of the bone. 2013. Available from: http://www.fda. gov/NewsEvents/Newsroom/PressAnnouncements/ucm356528.htm. Accessed May 5, 2015.

26. Chawla S, Henshaw R, Seeger L, et al. Safety and efficacy of denosumab for adults and skeletally mature adolescents with giant cell tumour of bone: interim analysis of an open-label, parallel-group, phase 2 study. Lancet Oncol. 2013;14(9):901-908.

27. Karras NA, Polgreen LE, Ogilvie C, Manivel JC, Skubitz KM, Lipsitz E. Denosumab treatment of metastatic giant-cell tumor of bone in a 10-year-old girl. J Clin Oncol. 2013;31(12):e200-e202.

28. George S, Merriam P, Maki RG, et al. Multicenter phase II trial of sunitinib in the treatment of nongastrointestinal stromal tumor sarcomas. J Clin Oncol. 2009;27(19):3154-3160.

29. Tse LF, Wong KC, Kumta SM, Huang L, Chow TC, Griffith JF. Bisphosphonates reduce local recurrence in extremity giant cell tumor of bone: a case-control study. Bone. Jan 2008;42(1):68-73.

30. Gouin F, Rochwerger AR, Di Marco A, et al. Adjuvant treatment with zoledronic acid after extensive curettage for giant cell tumours of bone. Eur J Cancer. 2014;50(14):2425-2431.

31. Martin-Broto J, Cleeland CS, Glare PA, et al. Effects of denosumab on pain and analgesic use in giant cell tumor of bone: interim results from a phase II study. Acta Oncol. 2014;53(9):1173-1179.
Biologics: Targets \& Therapy

\section{Publish your work in this journal}

Biologics: Targets \& Therapy is an international, peer-reviewed journal focusing on the patho-physiological rationale for and clinical application of Biologic agents in the management of autoimmune diseases, cancers or other pathologies where a molecular target can be identified. This journal is indexed on PubMed Central, CAS, EMBase, Scopus

\section{Dovepress}

and the Elsevier Bibliographic databases. The manuscript management system is completely online and includes a very quick and fair peerreview system, which is all easy to use. Visit http://www.dovepress com/testimonials.php to read real quotes from published authors. 